\title{
Antimicrobial resistance is a social problem requiring a social solution
}

\author{
We need to reverse our dependency on antibiotics, whether or not new ones are discovered
}

\author{
Richard Smith professor of health system economics and dean, Faculty of Public Health and Policy, \\ London School of Hygiene and Tropical Medicine
}

\begin{abstract}
Antimicrobial resistance has reasserted itself on the national and international agenda as a critical threat to public health and health systems. It undermines the very foundations of modern healthcare, from joint replacements to chemotherapy, threatens to reverse the decline in mortality and morbidity from infectious diseases, jeopardises animal health and welfare, and poses potentially crippling financial effects. ${ }^{12}$
\end{abstract}

It is intrinsically a biological phenomenon, which has, perhaps naturally, led to much of the discussion on tackling it being driven from a biological, and broader scientific, perspective. However, the conditions promoting, or militating against, the biological mechanisms of antimicrobial resistance are deeply social, shaped by cultural, political, and economic processes. Such social aspects include:

- The ways farmers, vets, and regulatory systems manage livestock production for human consumption

- How regulatory and fiscal frameworks incentivise or deter antimicrobial development, production, and use

- How the public and healthcare professionals understand, value, and use antimicrobials

- The context in which animals and humans interact, and

- The ways in which particular groups of people are exposed to particular microbial infections. ${ }^{3}$

Actions to reduce and control antimicrobial resistance will therefore involve change in social practices, but at present the discourse and, critically, the investment of time, money, and intellectual capital are heavily biased towards technological solutions.

\section{Narrow focus on drugs and tests}

Chief among these is the push for development of "novel" antimicrobials. For example, the latest report from the Independent Review on Antimicrobial Resistance, chaired by Jim O'Neill, emphasised the need for de-linking drugs' profitability from sales volumes. ${ }^{45}$ This builds on other recent work, such as that by the think tank on international affairs
Chatham House, which has outlined alternative business models to similarly change the current financial models for encouraging and supporting research and development in new antibiotics. ${ }^{6}$ Meanwhile, in practice, in the United States there has been an extension to marketing exclusivity, accelerated review, and a relaxation of requirements for approval by the Food and Drug Administration. ${ }^{7}$ Although this leniency may have increased the development and launch of new antibiotics, there is worrying evidence that such "fast tracking" may generate considerable adverse effects. ${ }^{8}$ Critical, of course, is the basic fact that because resistance to an antimicrobial begins as soon as it is developed, new agents can never be the sole solution - and certainly not necessarily the most cost effective or sustainable.

Mechanisms to promote the sustainable use of antimicrobials are also needed, but work has increasingly focused on rapid diagnostic tests to support the more "appropriate use" of antimicrobials. This was a key topic in the previous report from O'Neill's review. ${ }^{9}$ Research Councils UK is also supporting diagnostics development, ${ }^{10}$ and the influential Longitude Prize (https://longitudeprize.org) is to be awarded to whoever first develops a specific rapid diagnostic tool. But even if such tests are developed they can only ever be a partial solution, and their value will be negated by systemic factors, such as out-of-pocket payments increasing the risk of a course of antimicrobials not being completed, and relative costs making it more likely that antimicrobials would be used without the test, as antimicrobials are often very cheap. These and other factors all point to sustainable antimicrobial use requiring considerable behavioural, cultural, political, and economic change rather than just use of a diagnostic test to identify whether an infection is viral or bacterial or whether it is a sensitive or resistant infection.

\section{New vision needed}

This is not to suggest that social aspects are being ignored. However, trends in activity, in the balance of funding between basic and social science, and in political and popular opinion indicate that the vision for tackling antimicrobial resistance is 
focused on technological and biomedical solutions. This is deeply concerning. Although the mechanism for antimicrobial resistance is biological, the problem is fundamentally social: a problem of use and abuse and of modern health systems that depend heavily on antibiotics. As a social problem it demands a social solution, one based on greater understanding, measurement, modelling, and ultimately (re)shaping the social, political, and economic environment in which resistance develops and antibiotics are used. But this won't happen without a new vision for tackling antimicrobial resistance, backed by investment of time, money, and energy in the necessary social science research

The latest report from the O'Neill review recommends a global innovation fund of around $\$ 2 \mathrm{bn}$ ( $£ 1.3 \mathrm{bn} ; € 1.8 \mathrm{bn})$ to boost "blue sky" research into drugs and diagnostics and says that a comprehensive package of interventions in this area could cost "as little as \$16bn." That may be true, but even with those investments there is a risk that nothing will result. And any results we do get may only be buying time.

It would be more sustainable and effective to use such funds to support work to restructure our health systems and reverse our dependency on antibiotics, which ultimately we will need to do whether or not new antibiotics are discovered.

Competing interests: I am involved with Research Councils UK's cross council initiative; am a member of the Longitude Prize committee; was involved in the Economic and Social Research Council's working group on social science and antimicrobial resistance; and contributed to a
RAND report that was cited in Jim O'Neill's first report on antimicrobial resistance.

Provenance and peer review: Not commissioned, not externally peer reviewed.

thebmj.com Feature: Speeding new antibiotics to market-a fake fix? (BMJ 2015;350:h1453, doi:10.1136/bmj.h1453)

1 Smith RD, Coast J. Antimicrobial resistance: the true cost. BMJ 2013;346:20-2.

2 Review on Antimicrobial Resistance. Antimicrobial resistance: tackling a crisis for the health and wealth of nations. 2014. http://amr-review.org/sites/default/files/AMR\% 20Review\%20Paper\%20-\%20Tackling\%20a\%20crisis\%20for\%20the\%20health\%20and\% 20wealth\%20of\%20nations 1.pdf.

3 Economic and Social Research Council. Anti-microbial resistance: setting the social science agenda: report of an ESRC working group. Jul 2014.www.esrc.ac.uk/_images/ AMR-Setting-the-Social-Science-Agenda-report_tcm8-31249.pdf.

4 Wise J. Report calls for $\$ 2$ bn global fund to kickstart antibiotic development. BMJ 2015;350:h2635.

5 Review on Antimicrobial Resistance. Securing new drugs for future generations: the pipeline of antibiotics. 2015. http://amr-review.org/sites/default/files/SECURING\%20NEW\% 20DRUGS\%20FOR\%2OFUTURE\%20GENERATIONS\%20FINAL\%20WEB_0.pdf.

6 Outterson K. New business models for sustainable antibiotics. Chatham House, Feb 2014. www.chathamhouse.org/sites/files/chathamhouse/public/Research/Global\%20Health/ 0214SustainableAntibiotics.pdf.

7 Hatch O. Promise for antibiotics and therapeutics for health act or the PATH act. 2015 www.congress.gov/bill/114th-congress/senate-bill/185?q=\%7B\%22search\%22\%3A\%5B $\%$ 22 s. $185 \% 22 \% 5 \mathrm{D} \% 7 \mathrm{D}$

8 Doshi P. Speeding new antibiotics to market: a fake fix? BMJ 2015;350:h1453.

9 Review on Antimicrobial Resistance. Tackling a global health crisis: initial steps. 2015. http://amr-review.org/sites/default/files/Report-52.15.pdf.

10 Medical Research Council. Tackling AMR theme 2: accelerating therapeutic and diagnostics development EOI. 2014. www.mrc.ac.uk/funding/browse/tackling-amr-theme2-accelerating-therapeutic-and-diagnostics-development-eoi.

Cite this as: BMJ 2015;350:h2682

๑ BMJ Publishing Group Ltd 2015 